\title{
Dense and powder avalanches: momentum reduction generated by a dam
}

\author{
Florence NAAIM-BOUVET, Mohamed NAAIM, Thierry FAUG \\ UR ETNA, Cemagref Domaine universitaire, 2 rue de la Papeterie, BP 76, 38402 Saint-Martin-d'Hères Cedex, France \\ E-mail: florence.naaim@cemagref.fr
}

\begin{abstract}
Passive protection structures reduce avalanche run-out distance and hence the potential damages brought about by an avalanche, by reducing its velocity and mass. This paper starts with a summary of the main existing results on interactions between snow avalanches and dams. In the case of dense avalanches, the effects of dams are re-examined and previous results are theoretically justified. For a powder-snow avalanche a dam has two primary effects. The momentum is reduced by the retarding force upstream of the dam and when the jet collides with the ground after the dam. Entrainment of air during the jet reduces its velocity since the mass increases. For a dense avalanche, there is a retarding force upstream of the dam and when the jet collides with the ground, but there is no significant effect of air entrainment. There is, however, deposition of snow which reduces the momentum of the avalanche without affecting the velocity. The reduction of the volume due to deposition reduces the spreading length and therefore the run-out distance of the avalanche. Downstream of the obstacle, the avalanche flow is regarded as an airborne jet. A comparative study shows that density and ambient-fluid entrainment effects are significant for gravity currents, powder and dense snow avalanches whereas they are negligible in granular flows.
\end{abstract}

\section{INTRODUGTION}

Dams are usually designed to stop dense avalanches up to a certain volume. Above this volume, they act by retarding and stopping the flow of the avalanche. This paper focuses on that particular phase. A direct assessment of the efficiency of defence structures is obtained by quantifying momentum and mass reductions and the resulting consequences in terms of pressure and run-out distance. In the powder-snow avalanche case, the main effects are momentum reduction and ambient-fluid entrainment. The momentum is reduced through a retarding force upstream of the dam and when the jet collides with the ground downstream of the dam. Entrainment of air during the jet reduces its velocity since the mass increases. These effects are responsible for the avalanche pressure reduction. In the case of dense flows, momentum reduction generated by the upstream retarding force and by the collision of the jet with the ground is combined with mass reduction due to deposition upstream of the dam. These two processes contribute to the shortening of the avalanche run-out.

The momentum reduction results from three different phases: (i) flow-obstacle impact and deflection upstream of the dam, (ii) jet and ambient fluid entrainment, and (iii) jet impact on the ground downstream of the dam. Many previous works have evaluated the contribution of the first phase, but the contributions of the two last phases have often been neglected. This paper attempts to summarize, re-examine and improve the existing results on the first phase and to quantify the contributions of the second phase by studying the airborne jet and its interaction with the ambient fluid in terms of entrainment and friction for both avalanche types.
The following two sections summarize, re-examine and improve recent results on avalanche interactions with a dam. Section 4 is devoted to the analysis of the flow of the airborne jet downstream of the obstacle.

\section{POWDER-SNOW AVALANCHES}

In the past, several attempts have been made to simulate a powder avalanche. It is possible to distinguish three different approaches: (i) Hopfinger and Tochon-Danguy (1977) and Beghin and Olagne (1991) mainly employed density currents; (ii) Hermann and Hutter (1991) simulated powder-snow avalanches by a turbulent suspension flow of polystyrene particles in water; (iii) Bozhinskiy and Sukhanov (1998) modelled a dense avalanche with dry powder materials in air and studied the formation of the powder cloud, while McElwaine and Nishimura (2001) simulated collisional avalanche flows and their interaction with air using ping-pong ball experiments. In our experiments (NaaimBouvet and others, 2002) using the gravity-current concept, the avalanche consisted of a heavy fluid (kaolin particles suspended in salt water) dispersing in a lighter one (water). When the Reynolds number is sufficiently high (inertial phase), dynamic similarity is respected if the densimetric Froude number $F=U / \sqrt{g H\left(\Delta \rho / \rho_{\mathrm{a}}\right)}$ and the density ratio $\Delta \rho / \rho_{\mathrm{a}}=\left(\rho-\rho_{\mathrm{a}}\right) / \rho_{\mathrm{a}}$ are equal in nature and in the laboratory. $U$ is the downslope velocity, $H$ is the flow height, $\rho$ is the density of the mixture and $\rho_{\mathrm{a}}$ is the density of the ambient fluid. Satisfying Froude-number and density-ratio similarities in the laboratory means that a very high velocity is necessary, which calls for considerable channel dimensions. With water as ambient fluid, it is not possible to satisfy the 


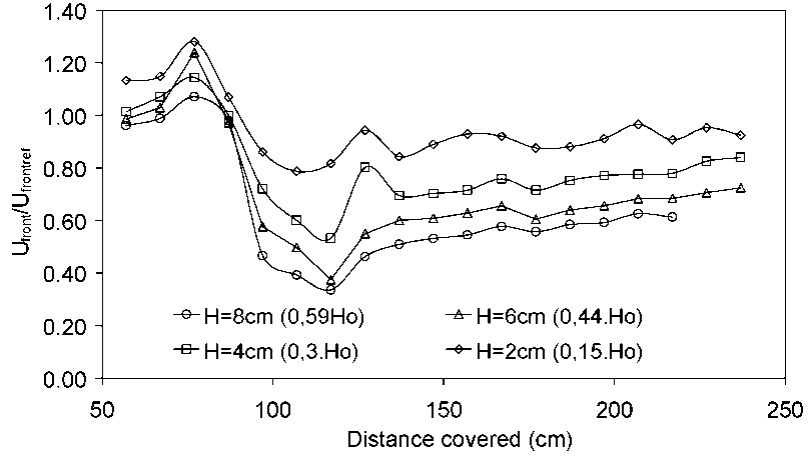

Fig. 1. Experimental values of $U_{\text {front }} / U_{\text {frontref }}$ as a function of distance for different dam heights. The dam is located at $97 \mathrm{~cm} . U_{\text {frontref }}$ is the front velocity of the reference avalanche without a dam.

density-ratio similarity, but the effects of a distortion in the density ratio on the flow variables have been studied using a numerical model in Hermann and others (1995) and Naaim and others (2003). For a high initial density ratio, a strong effect is observed mainly during the acceleration phase (rapid growth in size and velocity). When the flow is fully developed, the densimetric Froude similarity is approximately valid.

Only a few experiments have been attempted using physical modelling of the interaction between a gravity current and obstacles. A first attempt was made by Hopfinger and Tochon-Danguy (1977). Later, a series of experiments studying unsteady gravity current flows over deflecting and catching dams was conducted by Beghin and Closet (1990) and Augé and others (1995). The dynamic pressure was estimated from the front velocity, which was the only measured parameter. Experiments similar to those of Beghin and Closet (1990) have been carried out using Doppler ultrasonic velocimetry in order to measure the velocity inside the flow (Keller and Issler, 1996; Naaim-Bouvet and others, 2002).

The experimental set-up used in Naaim-Bouvet and others (2002) consisted of a $4 \mathrm{~m} \times 2 \mathrm{~m} \times 4.5 \mathrm{~m}$ water tank with glass walls. Buoyant clouds flowed along an inclined channel from a small immersed tank $(0.20 \mathrm{~m}$ length, $0.15 \mathrm{~m}$ width, $4 \times 10^{-3} \mathrm{~m}^{3}$ volume) with a release gate. The inertial phase (high velocity and turbulence) of powder avalanches was simulated by a heavy suspension (salt water and kaolin), which was dispersed into a lighter one. The density of the heavy suspension was $1200 \mathrm{~kg} \mathrm{~m}^{-3}$. The simulated avalanche was more a puff of non-continuous injected density than a current of heavy fluid: a finite volume of heavy suspension was released instantaneously from the small immersed tank. The avalanche track was confined to a channel (length $285 \mathrm{~cm}$, width $15 \mathrm{~cm}$, height $50 \mathrm{~cm}$ ). The experiments were carried out with and without an obstacle which was set up $97 \mathrm{~cm}$ from the gate, perpendicular both to the bottom plane and to the channel axis. This obstacle, with a height up to $8 \mathrm{~cm}$, obstructed the channel. Runs were made along a constant slope angle of $10^{\circ}$. The initial volume in the release tank was $2 \times 10^{-3} \mathrm{~m}^{3}$ for each trial. The experiments were quasi-two-dimensional. We determined experimentally that the highly turbulent nature of the avalanches required an average over five identical experiments. Two cameras were used (top and side views) to obtain the height, length, width and shape of the flow, together with the front

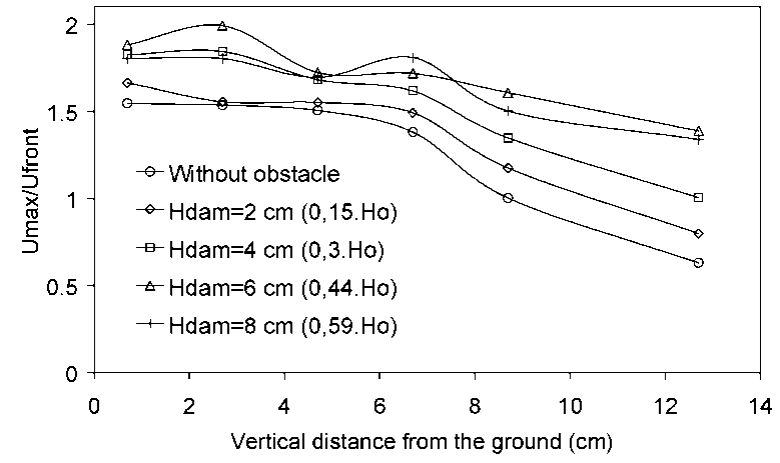

Fig. 2. Ratio between the maximum horizontal velocity and front velocity as function of height at $47 \mathrm{~cm}$ downstream of the dam (Naaim-Bouvet and others, 2002).

velocity. An array of two transducers coupled with the expanded ultrasonic unit was used to measure the component of the particle velocity vector in the direction of the transducer. Two directions ( $x$ direction and $y$ direction) were investigated. For the reference avalanche without obstacle, the "horizontal" velocity" (in the $x$ direction, i.e. parallel to the slope) inside the avalanche head was about 1.5 times the front velocity. This supports Hopfinger and Tochon-Danguy's (1977) results. The ratio $U_{\max } / U_{\text {front }}$ was greater than 1 in the lower part $(y<0.5 H)$ of the flowing avalanche. $U_{\max }$ is the maximum "horizontal" velocity in time at a fixed space point, and $U_{\text {front }}$ is the front velocity measured at the same space point. New and interesting results were obtained for the "vertical" velocity (in the $y$ direction, i.e. normal to the slope), which rose to $74 \%$ of the front velocity in a very short period.

The flow overran obstacles: the dam caused an acceleration of the flow above it and then a vortex appeared. This vortex acquired its circulation from the impulse due to the acceleration above the dam. As reported in Naaim-Bouvet and others (2002), the reduction in front velocity due to the presence of a dam was an increasing function of the dam height $47 \mathrm{~cm}$ downstream of the dam (Fig. 1). The ratio $U_{\max } / U_{\text {front }}$ was an increasing function of the dam height and reached a maximum value of 1.9 (Fig. 2). Consequently, the front velocity was not relevant in determining the effectiveness of dams. The obstacle led to a velocity reduction downstream of the vortex zone.

We also focus on what could be called "protected zone length" situated between the dam and the jet collision area. It consists of a small area just downstream of the dam. In our laboratory experiments, this relatively small region, determined by means of image processing, seems to be independent of the dam height (Fig. 3). This is mainly due to the strong entrainment of water inside the gravity current.

\section{DENSE-SNOW AVALANGHES}

The dense part of major avalanches with dry and cold snow is generally regarded as a granular flow. Many previous experimental works (Hutter and Koch, 1991; Greve and Hutter, 1993; Koch and others, 1994; Hutter and others, 1995; Gray and others, 1999) have confirmed that the SavageHutter model (Savage and Hutter, 1989), based on a Coulombian dry-friction term as the dominant momentum-loss mechanism, predicts the details of the motion of dry granular masses in the laboratory. However, this model seems to 
be only well adapted for high slopes with a smooth bed (Pouliquen and Forterre, 2002). A new empirical friction law has been formulated for dense gravity mass flows on rough beds (Pouliquen, 1999). This model has been shown to describe quite well low-Froude-number flows on lower slopes with a rough bed (Pouliquen and Forterre, 2002). This recent progress has been integrated in snow avalanche modelling (Naaim and others, in press), particularly in order to study the interaction of dense flows with obstacles. The constitutive law relevant to describe, with high precision, granular flows is still an open question. However, numerous studies have recently been carried out to better understand the interaction of these flows with obstacles. Two questions arise when a dense granular flow interacts with an obstacle. Each of them concerns a particular scale:

local effects: stagnant zone formation upstream of the obstacle (Chu and others, 1995; Faug and others, 2002; Naaim and others, 2003), jet formation downstream of the obstacle (Hákonardóttir and others, 2001, 2003) and dynamic pressure reduction (Naaim, 1998);

global effects: run-out shortening (Hákonardóttir and others, 2001; Faug and others, 2003) and deflection (Tai and others, 2001).

Both local and global effects were shown to be heavily linked to the flow regime. According to the Froude number, two distinct flow regimes can be identified:

A low-Froude-number regime (or storage regime) where the deposition process upstream of the obstacle is dominant. It leads to a shortening of the run-out which is heavily dependent on the volume retained. The rheology of the material is crucial for this regime.

A high-Froude-number regime (or inertial regime) for which local momentum loss is dominant. It leads to a significant run-out shortening. The rheology of the material is not crucial in this case.

The Froude number of dense-snow avalanches is generally between 0 and 15, depending on different parameters such as snow types or flow phases (release, acceleration, deceleration...). Thus, dense-snow avalanches can exhibit both flow regimes.

According to the desired effects (momentum reduction or storage), dams are generally set up at the end of the flow zone (high Froude number) or in the run-out zone (intermediate or low Froude number). A series of experiments with different granular materials at different scales were performed concerning the influence of the dimensionless obstacle height $H_{\text {dam }} / H_{0}$ (ratio of the obstacle height to the reference flow depth at the same location) on the runout shortening $D_{\text {dam }} / D_{0}$ (ratio of the run-out distance with obstacle to the run-out distance without obstacle) (Hákonardóttir and others, 2001; Faug and others, 2003).

The run-out shortening results from: (i) the local momentum loss generated by impact on the dam, flow deflection, jump and impact on the ground, and (ii) the reduction of the volume of the avalanche which limits the spreading length.

The total run-out distance of a given avalanche without any obstacle can be written as the sum of the run-out of the centre of mass $\left(D_{0-\mathrm{cm}}\right)$ and half of the spreading length in the stopping zone $\left(D_{0-s}\right)$ :

$$
D_{0}=D_{0-\mathrm{cm}}+D_{0-s}
$$

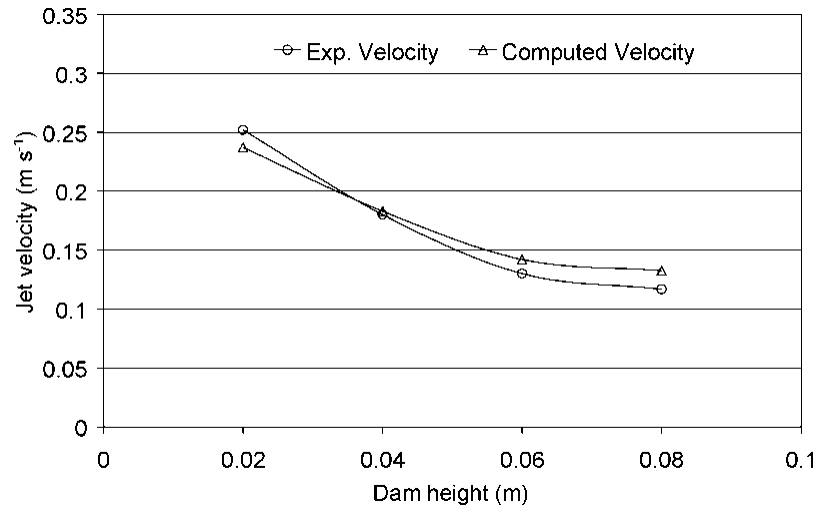

Fig. 3. Gravity current: dimensionless jump length as function of dam height (average 15 runs $/ H_{0}=13.5 \mathrm{~cm}$ ).

The total run-out distance of the avalanche impacting a thin obstacle can be written as the sum of the run-out of the centre-of-mass $\left(D_{\text {dam-cm }}\right)$ and one-half of the spreading length in the stopping zone $\left(D_{\mathrm{dam}-s}\right)$ :

$$
D_{\text {dam }}=D_{\text {dam }-\mathrm{cm}}+D_{\text {dam }-s} \text {. }
$$

The total run-out shortening generated by a dam is then given by:

$$
D_{0}-D_{\text {dam }}=\left(D_{0-\mathrm{cm}}-D_{\text {dam-cm }}\right)+\left(D_{0-s}-D_{\text {dam }-s}\right)
$$

If $u_{\text {up }}$ is the velocity upstream of the dam and $u_{\text {down }}$ the velocity of the avalanche after the impact of the jet on the ground, the centre-of-mass run-out distances can be written as follows:

$$
\begin{gathered}
D_{0-\mathrm{cm}}=\frac{u_{\mathrm{up}}^{2}}{\mu g \cos \theta} \\
D_{\text {dam-cm }}=\frac{u_{\text {down }}^{2}}{\mu g \cos \theta}+D_{\text {jump }} .
\end{gathered}
$$

$g$ is the acceleration due to gravity, $\theta$ is the slope angle, $D_{\text {jump }}$ is the length of the jump and $\mu$ is the effective friction coefficient at the bottom. These results hold if the external forces are velocity-independent.

$$
D_{0-\mathrm{cm}}-D_{\text {dam-cm }}=D_{0-\mathrm{cm}}\left(1-\frac{u_{\text {down }}^{2}}{u_{\mathrm{up}}^{2}}\right)-D_{\text {jump }}
$$

If the deposit obtained with the dam is geometrically similar to the deposit without the dam, then:

$$
\frac{\left(D_{0-\mathrm{s}}-D_{\mathrm{dam}-\mathrm{s}}\right)}{D_{0-s}}=1-\left(1-\frac{V_{\mathrm{s}}}{V_{\mathrm{t}}}\right)^{\frac{1}{3}},
$$

where $V_{\mathrm{t}}$ is the initial volume and $V_{\mathrm{s}}$ is the volume retained upstream of the dam.

The total run-out shortening can be written as follows:

$$
\begin{aligned}
& D_{0}-D_{\text {dam }}=D_{0-\mathrm{cm}}\left(1-\frac{u_{\text {down }}^{2}}{u_{\text {up }}^{2}}\right) \\
& +D_{0-s}\left[1-\left(1-\frac{V_{\mathrm{s}}}{V_{\mathrm{t}}}\right)^{\frac{1}{3}}\right]-D_{\text {jump }} .
\end{aligned}
$$

This new formulation shows the contribution of the two processes more clearly than in Faug and others (2003). The run-out shortening due to the momentum loss is distinguished from the run-out shortening due to the avalanche volume reduction.

$$
\text { If we assume }\left[1-\left(u_{\text {down }}^{2} / u_{\mathrm{up}}^{2}\right)\right] \text { and }\left\{1-\left[1-\left(V_{\mathrm{s}} / V_{\mathrm{t}}\right)\right]^{\frac{1}{3}}\right\}
$$




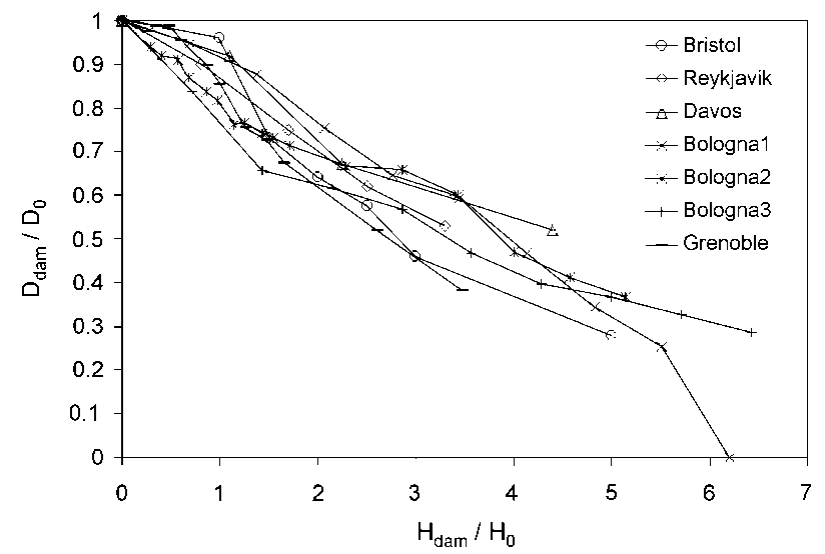

Fig. 4. Granular flows: dimensionless run-out vs dimensionless obstacle height.

proportional to $H_{\mathrm{dam}} / H_{0}$, the run-out shortening decreases linearly with $H_{\text {dam }} / H_{0}$ as evidenced by the experimental data plotted in Figure 4.

\section{POWDER AND DENSE AVALANGHES: JET ANALYSIS}

\subsection{Jet modelling}

The avalanche flow downstream of the obstacle is regarded as an airborne jet moving in an ambient fluid with zero velocity. It loses momentum due to drag caused by accelerating the ambient fluid. Entrainment of the ambient fluid increases its mass without affecting the momentum, thus decreasing the velocity and decreasing the density.

The following notation is used: $t$ is the time, $(x, y)$ is the coordinate system, $\rho$ is the jet's average density, $\vec{u}$ its velocity, $S$ its external surface, $V$ its volume, and $\vec{g}$ is the acceleration due to gravity.

The momentum conservation law applied to the jet gives:

$$
\begin{gathered}
\frac{\mathrm{d}(\rho V \vec{u})}{\mathrm{d} t}=\rho V \frac{d \vec{u}}{\mathrm{~d} t}+\vec{u} \frac{\mathrm{d}(\rho V)}{\mathrm{d} t}=\left(\rho-\rho_{\mathrm{a}}\right) V \vec{g}-\vec{F}_{\mathrm{r}} \\
\frac{\mathrm{d} \vec{u}}{\mathrm{~d} t}=\frac{\rho-\rho_{\mathrm{a}}}{\rho} \vec{g}-\frac{\vec{F}_{\mathrm{r}}}{\rho V}-\frac{\vec{u}}{\rho V} \frac{\mathrm{d}(\rho V)}{\mathrm{d} t} .
\end{gathered}
$$

$\vec{F}_{\mathrm{r}}$ is the surface ambient-fluid drag: $\vec{F}_{\mathrm{r}}=\lambda S \rho_{\mathrm{a}} \vec{u}\|\vec{u}\|$, where $\lambda$ is the turbulent friction coefficient.

The turbulent shear between the jet and the ambient fluid entrains the ambient fluid, so the solid volume fraction of the jet changes. This entrainment is proportional to the shear at the surface of the airborne jet. We considered the ambient-fluid entrainment rate given by:

$$
\frac{\mathrm{d}(\rho V)}{\mathrm{d} t}=\gamma S \rho_{\mathrm{a}}\|\vec{u}\| \text {. }
$$

The final expression for the equation of motion is then:

$$
\frac{\mathrm{d} \vec{u}}{\mathrm{~d} t}=\frac{\rho-\rho_{\mathrm{a}}}{\rho} \vec{g}-\frac{S \rho_{\mathrm{a}}}{V \rho} \xi \vec{u}\|\vec{u}\| ; \xi=\lambda+\gamma .
$$

This model was used to reproduce three different small- and intermediate-scale experiments corresponding to laboratory gravity currents, laboratory dense granular flows and dense-snow flows on a chute.

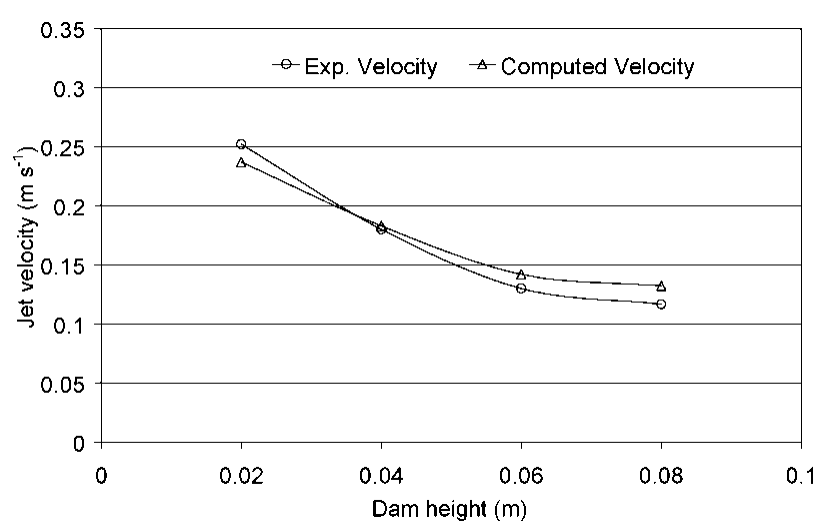

Fig. 5. Comparison between computed and experimental velocities $20 \mathrm{~cm}$ downstream of the dam in the case of gravity current.

\subsection{Gravity-current case}

In the case of a gravity current, the results given by this simple model are relevant. They quantify the role of the entrainment of ambient fluid.

The back-calculation of the experiments by Naaim-Bouvet and others (2002) showed that the entrainment of ambient fluid significantly modifies the jet characteristics. The volume of the airborne jet changes and its mass increases significantly, while its velocity and trajectory length are reduced.

The model was first calibrated on four experiments. The input parameters of the airborne jet were: dam height $(0.02$, $0.04,0.06$ and $0.08 \mathrm{~m})$ and velocity $\left(0.3,0.25,0.15,0.17 \mathrm{~m} \mathrm{~s}^{-1}\right)$. The values of $\lambda \approx 1 \times 10^{-3}$ and $\xi \approx 0.4$ were determined from the data.

The diameter of the jet increases during its flying phase due to the ambient-fluid incorporation. When the jet collides with the ground, its higher limit collides far from the dam when its lower limit collides approximately at a constant distance $(0.05 \mathrm{~cm})$ from the dam whatever the dam height is.

The experimental results concerning the velocity of the jet $20 \mathrm{~cm}$ downstream of the dam were well reproduced by the model as shown in Figure 5. Another important point concerns the trajectory of the lower limit of the airborne jet. Both in the experimental and in the numerical results, the distances covered by the jet lower limit were 0.04$0.05 \mathrm{~m}$.

\subsection{Granular and dense avalanche cases}

In the case of dense avalanche flows, where the ratio between the density of the airborne jet and the ambient fluid density is large, we computed, using the model calibrated above, many experiments of granular flows reported by Hákonardóttir and others (2001). The input data were the dimensionless dam height $H_{\text {dam }} / H_{0}=1.1,2.2,4.4$, the horizontal velocity $u=2.85,2.4,1.3 \mathrm{~m} \mathrm{~s}^{-1}$ and the vertical velocity $w=1.21,1.44,1.5 \mathrm{~m} \mathrm{~s}^{-1}$. The comparison between the computed data and experimental data showed that the effect of the ambient-fluid entrainment is not significant (Fig. 6).

Two other experiments from Hákonardóttir and others (2003), involving dense snow, were simulated. The input parameters were the dam height $(0.4$ and $0.6 \mathrm{~m})$, the horizontal velocity $\left(u=6.2\right.$ and $\left.3.52 \mathrm{~ms}^{-1}\right)$ and the vertical 


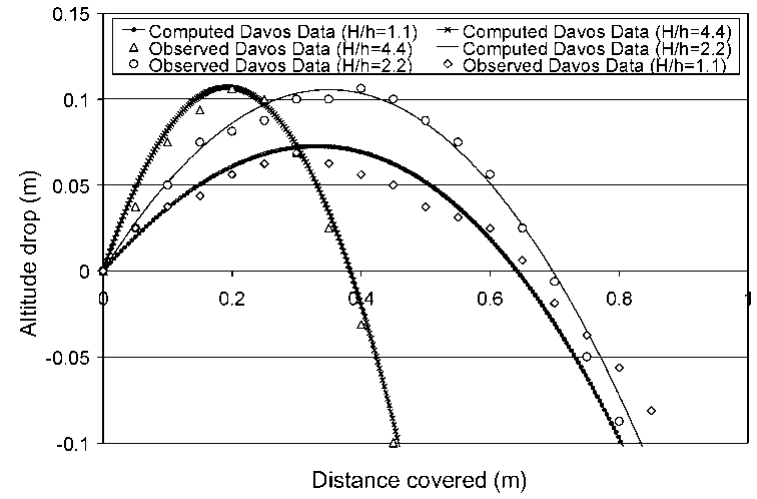

Fig. 6. Comparison between observed data (Hákonardóttir and others, 2001) and computed data.

velocity $\left(w=2.25\right.$ and $\left.1.88 \mathrm{~m} \mathrm{~s}^{-1}\right)$. The model reproduced these experiments well as illustrated in Figure 7.

\subsection{Flying phase: entrainment effects on gravity cur- rents and granular, dense and powder avalanches}

Whatever the initial behaviour of the avalanche (dense, powder, gravity current), the flying flow phase generated by the dam is governed by Equation (12).

The considered flows (granular, dense flow, powder flow and gravity current) occur at different densimetric Froude number: typically 5-10 for granular- and dense-flow avalanches, 1-3 for powder-snow avalanches and near 1 for gravity currents in the laboratory. The objective of this subsection is to evaluate the effects of the air entrainment on four different airborne jets generated by granular flow, dense flow, powder flow and gravity-currents flow. The momentum losses of the airborne jet are governed by the gravity force and the ambient-fluid drag and entrainment. The ratio between the contributions of the two effects is approximated by:

$$
f \approx \frac{\rho_{\mathrm{a}}}{\rho} \xi \frac{4\|\vec{u}\|^{2}}{\frac{\rho-\rho_{\mathrm{a}}}{\rho} g d} \approx 4 \frac{\rho_{a}}{\rho} \xi F^{2} .
$$

The relative contribution of the ambient-fluid effects (indexed $e$ ) is then given by:

$$
e=\frac{\text { Ambient fluid effects }}{\text { Gravity }+ \text { Ambient fluid effects }}=\frac{f}{1+f} .
$$

Table 1 displays the values of $e$ for the considered flows. It shows significant differences between them. For granular

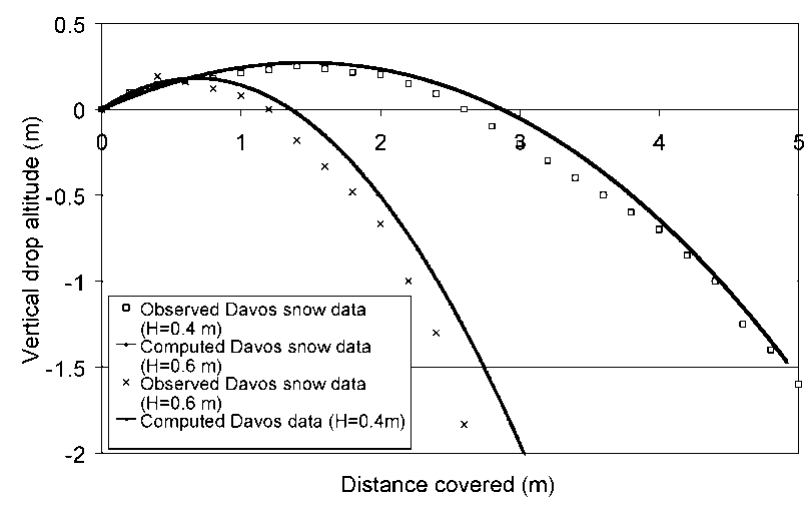

Fig. 7. Comparison between observed data (Hákonardóttir and others, 2003) and computed data for trajectories at the Davos snow chute.
Table 1. Relative contribution of the ambient fluid effects for granular flow, dense avalanche, powder avalanche and gravity current

\begin{tabular}{lcccc}
\hline Flow & Densimetric Froude number & $\rho$ & $\rho_{\mathrm{a}}$ & $e$ \\
& & $\mathrm{~kg} \mathrm{~m}^{-3}$ & $\mathrm{~kg} \mathrm{~m}^{-3}$ & \\
& & & & \\
\hline Granular & $5-10$ & 2000 & 1.0 & $0.005-0.01$ \\
Dense & $5-10$ & 200 & 1.0 & $0.05-0.09$ \\
Powder & $1-3$ & 10 & 1.0 & $0.18-0.4$ \\
Gravity current & 1 & 1100 & 1000 & 0.6 \\
& & & & \\
\hline
\end{tabular}

flow the entrainment effects are negligible. They represent $5-10 \%$ in the case of dense avalanches, $10-40 \%$ for powder avalanches and around $60 \%$ for gravity currents.

\section{CONGLUSION}

In this paper, we studied the action of a thin dam on avalanche flows. We considered two parameters. The flow was represented by its densimetric Froude number, and the dam was represented by its height. The avalanche dense flows were regarded as granular flows, and the powder avalanches as inertial gravity currents. Several experiments were performed both for granular and for inertial gravity currents. The experiments allowed us to quantify: (i) the momentum reduction for both kinds of flows and (ii) the run-out distance shortening for dense flows. In the latter case, the new formulation developed in this paper clearly distinguishes the effects of momentum reduction from those of mass reduction on the run-out distance shortening.

The momentum reduction due to the airborne jet (flying phase) is also studied and modelled using a simple jet theory. The model was calibrated using experimental results obtained in the case of gravity-current laboratory simulations. This model was thereafter successfully used to reproduce dense granular flying avalanches in terms of both velocity and trajectories without any new calibration.

The contribution of the ambient-fluid entrainment to the dynamics of four different airborne jets, corresponding to granular flows, dense flows, powder flows and gravitycurrent flows, was studied. The following conclusions were obtained. The influence of the ambient fluid was found negligible for granular flows. The ratio between the entrainment effects (drag and ambient-fluid incorporation) and the gravity force strongly depends on the densimetric Froude number. It was found to be up to $10 \%$ for dense avalanches, $40 \%$ for powder avalanches and $60 \%$ for gravitycurrent flows.

\section{ACKNOWLEDGEMENTS}

This work received significant financial support from the European Union within the framework of the EU-FP5-project CADZIE. The scientific exchanges within this project with the partners such as the Icelandic Meteorological Office (IMO), the Norwegian Geotechnical Institute (NGI) and the Swiss Federal Institute for Snow and Avalanche Research (SLF) helped to strengthen the quality of the research. 


\section{REFERENCES}

Augé, A., F. Ousset and O. Marco. 1995. Effet d'une digue sur l'écoulemen d'un aéorosol. In Sivardière, F. ed. Les apports de la recherche scientifique à la sécurité neige, glace et avalanche/The contribution of scientific research to safety with snow, ice and avalanche. Actes de Colloque, Chamonix 30 mai-3 juin 1995. Grenoble, Association Nationale pour l'Étude de la Neige et des Avalanches (ANENA), 235-240.

Beghin, P. and J.-F. Closet. 1990. Effet d'une digue sur l'écoulement d'une avalanche poudreuse. Grenoble, Centre National du Machinisme Agricole du Génie Rural des Eaux et des Forêts. (Informations Techniques du CEMAGREF 77, Note 3.)

Beghin, P. and X. Olagne. 1991. Experimental and theoretical study of the dynamics of powder snow avalanches. Cold Reg. Sci. Technol., 19(3), 317-326.

Bozhinskiy, A. N. and L. A. Sukhanov. 1998. Physical modelling of avalanches using an aerosol cloud of powder materials. Ann. Glaciol., 26, 242-246.

Chu, T., G. Hill, D. M. McClung, R. Ngun and R. Sherkat. 1995. Experiments on granular flows to predict avalanche runup. Can. Geotech. F., 32(2), 285-295.

Faug, T., P. Lachamp and M. Naaim. 2002. Experimental investigation on steady granular flows interacting with an obstacle down an inclined channel: study of the dead zone upstream from the obstacle. Application to interaction between dense snow avalanches and defence structures. Nat. Hazards Earth System Sci., 2(3-4), 187-191.

Faug, T., M. Naaim, D. Bertrand, P. Lachamp and F. Naaim-Bouvet. 2003. Varying dam height to shorten the run-out of dense avalanche flows: developing a scaling law from laboratory experiments. Surv. Geophys., 24(5-6), 569-585.

Gray, J. M. N. T., M. Wieland and K. Hutter. 1999. Gravity driven free surface flow of granular avalanches over complex basal topography. Proc. $R$. Soc. London, Ser. A 455, 1841-1874.

Greve, R. and K. Hutter. 1993. Motion of a granular avalanche in a convex and concave curved chute: experiments and theoretical predictions. Philos. Trans. R. Soc. London, Ser. A, 342(1666), 573-600.

Hákonardóttir, K.M., T. Jóhannesson, F. Tiefenbacher and M. Kern. 2001. A laboratory study of the retarding effect of breaking mounds in 3, 6 and $9 \mathrm{~m}$ long chutes. Reykjavik, Veðurstofa Íslands. (Technical report VI-G01007ÚR02.).

Hákonardóttir, K. M., T. Jóhannesson, F. Tiefenbacher and M. Kern. 2003. Large-scale avalanche braking mound and cathing dam experiments with snow: a study of the airbourne jet. Surv. Geophys., 24(5-6). 543-554
Hermann, F. and K. Hutter. 1991. Laboratory experiments on the dynamics of powder snow avalanches in the run-out zone. f. Glaciol., 37(126), 281-295.

Hermann, F., D. Issler and S. Keller. 1995. Numerical simulations of powder snow avalanches and laboratory experiments on turbidity currents. In Buisson, L. and G. Brugnot, eds. Pierre Beghin Workshop on Rapid Gravitational Mass Movements, December 6-10, 1993, Grenoble. Proceedings. Grenoble, Editions CEMAGREF, 137-144.

Hopfinger, E. J. and J.-C. Tochon-Danguy. 1977. A model study of powdersnow avalanches. F. Glaciol., 19 (81), 343-356.

Hutter, K. and T. Koch. 1991. Motion of a granular avalanche in an exponentially curved chute: experiments and theoretical predictions. Philos. Trans. R. Soc. London, Ser. A, 334(1633), 93-138.

Hutter, K., T. Koch, C. Plüss and S. B. Savage. 1995. The dynamics of avalanches of granular materials from initiation to runout: Part II. Laboratory experiments. Acta Mech., 109, 127-165.

Keller, S. and D. Issler. 1996. Staublawinen über Dämme und Mauern im Labor, Zusammenstellung aller Resultate und Auswertung. Internal report no. 697, April. Davos, Swiss Federal Institute for Snow and Avalanche Research.

Koch, T., R. Greve and K. Hutter. 1994. Unconfined flow of granular avalanches along a partly curved surface. 2. Experiments and numerical computations. Proc. R. Soc. London, Ser. A, 445(1924), 415-435.

McElwaine, J. and K. Nishimura. 2001. Ping-pong ball avalanche experiments. Ann. Glaciol., 32, 241-250.

Naaim, M. 1998. Dense avalanche numerical modeling. Interaction between avalanche and structures. In Hestnes, E., ed. 25 Years of Snow Avalanche Research, Voss, 12-16 May 1998. Proceedings. Oslo, Norwegian Geotechnical Institute, 187-191. (NGI Publication 203.)

Naaim, M., ed. 2003. CADZIE/Catastrophic avalanches/Defence structures and zoning in Europe. Final report. Grenoble, Editions Cemagref, EVGI-199900009 .

Naaim-Bouvet, F., M. Naaim, M. Bacher and L. Heiligenstein. 2002. Physical modelling of the interaction between powder avalanches and defence structures. Nat. Hazards Earth System Sci., 2 (3-4), 193-202.

Pouliquen, O. 1999. Scaling laws in granular flows down rough inclined planes. Phys. Fluids, 11 (2-3), 542-548.

Pouliquen, O. and Y. Forterre. 2002. Friction law for dense granular flows: application to the motion of a mass down a rough inclined plane. F. Fluid Mech. 453, 133-151.

Savage, S. B. and K. Hutter. 1989. The motion of a finite mass of granular material down a rough incline. F. Fluid Mech., 199, 177-215.

Tai, Y. C., J. M. N. T. Gray, K. Hutter and S. Noelle. 2001. Flow of dense avalanches past obstructions. Ann. Glaciol., 32, 281-284. 